\title{
Social Justice and Adaptation in the UK
}

\author{
Magnus Benzie $^{1}$
}

\begin{abstract}
Adaptation strategies and policies are normally based on climate impact assessments that fail to take account of the social nature and distribution of vulnerability to climate change. This is largely a product of the dominant assessment techniques that are used to inform such strategies and the limits of existing evidence. In this paper I contribute to filling gaps in the current adaptation literature by exploring the social nature of vulnerability and the potential for socially just adaptation. It does so by reviewing studies from the UK, in particular those under the Joseph Rowntree Foundation's Climate Change and Social Justice programme. It finds that vulnerability to high temperatures and fluvial and coastal flooding, in terms of sensitivity, exposure, and the capacity to anticipate, respond, and recover, is concentrated in certain disadvantaged and socially marginalized groups, including those on low incomes. It also finds that both autonomous and planned adaptation may fail to protect the most vulnerable individuals and groups, and may even reinforce existing patterns of vulnerability in some cases, i.e., mal-adaptation, especially where they rely on unmediated market forces or where they fail to explicitly recognize aspects of social vulnerability in their design and implementation. I argue that social justice should be an explicit objective of adaptation strategy.
\end{abstract}

Key Words: adaptation; social justice; vulnerability

\section{INTRODUCTION}

In recent years research and policy have begun to focus on the need to adapt to inevitable climate change. This requires decision makers at a range of scales, global to local, sectoral, etc., to assess the likely impacts of climate change to identify priorities for adaptation (Brown et al. 2011). To date, few adaptation assessments have considered the uneven distribution of climate impacts and vulnerability across groups and individuals within society. This is partly a result of the tools and methods that are used to inform adaptation policy. Another reason is that the task of assessing individuals' and groups' vulnerability to future change is highly complex, given large uncertainties about the direction and pace of future socioeconomic and climatic trends and events. This makes it difficult to say with certainty which groups or individuals are most vulnerable. Here, vulnerability to climate change, climate variability, and extreme events are defined as a function of exposure to climate impacts, sensitivity to those impacts, and the adaptive capacity of the people or systems impacted (following Blaikie et al. 1994, IPCC 2007).

In this paper I take as a premise that society should and does care about social justice as a core value ${ }^{[1]}$. I also take the perspective that when assessing the impacts of climate change, the focus should be on who suffers, how much, when and how, and that adaptation should aim to be equitable as well as effective, efficient, and legitimate (after Adger et al. 2005). Adaptation should therefore strive to be socially just and to protect those who are most vulnerable to climate impacts.

\section{Adaptation research and methods}

Adaptation outcomes will only be as good as the methods and evidence used to inform adaptation decisions. Adaptation decision support methods include climate science, risk assessment, economic analyses, and vulnerability assessment.

\section{Climate science}

Decision makers take adaptation seriously because of the messages provided by climate science. Various general circulation models are used to project scenarios of future climate, which can be downscaled to model local-level impacts, e.g., precipitation, run-off, flooding, etc. Information of this type can be used to assess the likelihood and severity of future changes in climate and thereby identify priorities for adaptation. Methodologies based on this kind of top-down approach can loosely be termed "impacts-based" (see Brown et al. 2011).

Impacts-based approaches tend to focus on physical and natural systems rather than social systems. This is because the drivers and mechanics of these systems are better known and already modeled to some extent in most cases. Models of the impacts of climate change on hydrology, including flooding, and coastal change are therefore fairly common (HR Wallingford 2012); new models of physical systems, e.g., urban heat islands, are emerging (e.g., Hoffmann et al. 2012).

Social systems are highly complex and are rarely modeled as such. Human actors respond to a range of stimuli in often irrational and highly context-specific ways, which makes it difficult to simulate human decisions at the societal scale in models (Goldspink 2000). For example, it is more difficult to model how an individual will respond to a flood than it is to model how a river system will respond to heavy rain. The result is that scienceled, impacts-based approaches fail to represent the social nature of climate impacts.

\section{Risk assessment}

Climate science and impacts model results can be used in a variety of ways to support actual decisions. One of the most commonly advocated methods to support adaptation is to follow a risk management framework (Willows and Connell 2003, Jones and Preston 2011). Risk management is particularly appropriate because of the pervasive uncertainty involved with adaptation decisions.

One way to undertake a climate risk assessment is to identify a long list of potential impacts and then to scientifically assess their likelihood and magnitude to identify a level of risk (Brown et al. 2011). This sort of risk assessment can be seen as a continuation of an impacts-based approach to adaptation decision making. It implies that there is a value-neutral or scientific measurement of risk. 
An alternative approach is objective-based risk identification (Institute of Risk Management 2002). This involves the assessment of a number of possible "risk drivers" on the cost or potential for achieving an explicit set of objectives. This sort of approach is more common in project or corporate risk assessment. It is equally applicable to policy-based organizations or governments, however. It requires decision makers to be explicit about their objectives, which often involves making normative choices of about what is most important, or what should be achieved. The civil servants and advisors who often undertake climate risk assessments aim to appear neutral in terms of future policy choices and are therefore often reluctant to specify strategic objectives. It is sometimes considered safer not to state normative preferences and base adaptation decision making on some valuefree, scientific (impacts-based) approach.

However, Bradbury (1989) argues that risk management is better when it is based on openly subjective preferences about what is important to society. If policy makers can be explicit about their objective to, for example, improve the quality of life for all citizens, or to reduce social inequalities, then objective-based risk assessments hold significant potential for capturing the social nature of climate impacts, risks, and vulnerability.

\section{Economic analyses}

Adaptation decisions can also be supported by economic analyses, including social or project cost benefit analysis (CBA) and, at the global scale, integrated assessment modeling (IAM). The objective of these tools is to identify efficient or optimal policy choices, not to consider equity as a priority criterion.

Information on the costs of climate impacts and the benefits of adaptation are limited for most impacts and in most sectors (Watkiss 2011). However, investment decisions need to be informed by analysis of available options and in some instances, where investment costs and the value of avoided damages can be relatively well understood, e.g., for physical flood defences, CBA is an important and effective decision support tool. Social CBA seeks to maximize welfare from a utilitarian perspective, meaning that there might be winners and losers from an investment, but it will remain attractive as long as the winners are able to compensate the losers and still be better off. However, the distribution of the costs and (dis)benefits from social CBA for adaptation rarely receive much attention, and some argue that the treatment of time preference in CBA via discount rates also raises questions of intergenerational justice (e.g., Ackerman 2009). Similarly, the use of IAMs to inform decisions on adaptation policy design fails to shed light on social inequality or justice issues and may overestimate society's ability to adapt because of the crude representation of adaptation decisions in such models (see Patt et al. 2009, Stanton et al. 2009). Economic analyses, although important in many respects, therefore fail to adequately account for the distribution of climate impacts across society.

The use of impacts-based approaches can be generally characterized as "top-down" (Dessai and Hulme 2004). Topdown approaches, because they are based on climate scenarios, focus on exposure to harm and tend to see vulnerability as an "end-point" (Kelly and Adger 2000) or an "outcome" (O'Brien et al. 2007) and therefore static, as opposed to part of a social process. Top-down approaches, including relatively highresolution maps or indicators, can also imply that vulnerability is heterogeneous across groups or places, which may be inaccurate and stigmatize certain people or places as being "high risk" (Benzie et al. 2011). An advantage of top-down assessments, however, is that they can generally be carried out for a large geographical area, for example across a country, or indeed globally.

\section{Vulnerability assessment}

Bottom-up approaches, also known as vulnerability-based assessments, on the other hand, tend to focus on the impacts of current climate variability and the underlying causes and processes that cause some people to be more vulnerable than others to those impacts (an example is Brown and Walker 2008). In this way, they place a greater emphasis on adaptive capacity rather than exposure in assessing vulnerability and try to avoid seeing vulnerability as an inevitable effect of certain socioeconomic characteristics (Spiers 2000). Bottom-up approaches are more likely to incorporate people's own perception of vulnerability and attitudes toward risk, which may ultimately be more important than exposure in determining who adapts and who suffers during climate events. A disadvantage of bottom-up assessments is that they are resource-intensive and generally only apply to specific local areas. A number of qualitative, mostly bottom-up, studies on the social nature of vulnerability to climate change are referred to below.

\section{The UK Climate Change Risk Assessment}

The UK has generally been considered a forerunner in adaptation. For example, it has initiated various state-of-the-art processes and projects in relation to climate science, including the production of UK Climate Projections User Interface (http://ukclimateprojections. metoffice.gov.uk/) and the establishment of the UK Climate Impacts Programme in 1997 to support stakeholders and decision makers in using climate science to achieve adaptation. In 2008 the UK parliament passed the Climate Change Act, which, among other things, created a duty to conduct a Climate Change Risk Assessment (CCRA) every five years. The first CCRA was laid before Parliament in January 2012, with an accompanying report on the economics of climate resilience (ECR) completed in 2013. The reports will play an important role in influencing the UK National Adaptation Programme 2013 and its implementation.

The CCRA includes features of both a top-down, impacts-based assessment and an objective-based one. It takes as its starting point a list of over 700 impacts, identified after considering climate projections, reviewing existing evidence, and consulting with stakeholders. This long list of impacts was reduced to around 100 key risks, using a methodology that considered the magnitude of the impact and the level of confidence associated with the evidence (HR Wallingford 2010). The CCRA aims to identify all climate risks to the UK, but also considers risks in light of key government objectives, not least as the result of risk identification processes that consider Departmental Adaptation Plans, which themselves look at key departmental policies when identifying climate risks (HR Wallingford 2010).

The CCRA is based on a series of 12 sectoral assessments, each of which is led by a separate sector expert and team. The sectors covered by the CCRA include: agriculture, biodiversity and ecosystem services, built environment, business, industry and services, energy, floods and coastal erosion, forestry, health, marine and fisheries, transport, and water. This has implications 
for the way in which social issues are captured - or missed - in the assessment. Many if not all of these 12 sectors can be relevant to social justice and inequality in some way; built environment, floods and coastal erosion, health, and water are perhaps most relevant. However, by taking a sector approach, there is a danger that impacts are considered in terms of their effect on the functioning of the sectoral system and not on the lives of people affected by that system, e.g., focus on the number of people suffering from heat stress, rather than which people in society are likely to suffer harm as a result of heat stress.

Another key feature of the CCRA, and the ECR report, is that they are both based on existing evidence. The majority of climate change research, particularly quantitative analyses, has taken place within the fields of physical and natural science. CCRA and ECR results are therefore likely to be skewed by the available evidence (Prof. Martin Parry, CCRA Synthesis Report Peer Review, unpublishedmanuscript) and may underestimate the social nature of vulnerability and risk.

As well as underestimating the social nature of risk, the scope of the CCRA was limited to impacts within the UK, although as recent evidence suggests, indirect impacts on the UK resulting from climate change elsewhere in the world may be as significant, if not more so, than direct impacts at home (Foresight 2011). In particular, of the indirect impacts identified in the Foresight report, health, security and migration impacts may affect some groups in society more than others.

The CCRA is the first national assessment of its kind and embodies the proactive approach to adaptation policy being taken in the UK. However, for various methodological reasons, not least the reliance on existing evidence, the first iteration of the CCRA may undervalue the social nature of climate impacts, risks, and vulnerability. The resulting policies may thus also fail to protect the most vulnerable members of UK society.

\section{Social justice and climate change}

Recognizing this possibility, the Joseph Rowntree Foundation (JRF), a social policy research and development charity in the UK, initiated a research program on Climate Change and Social Justice (http://www.jrf.org.uk/work/workarea/climate-change-andsocial-justice). The JRF program has funded various projects to improve the evidence base on the links between social justice and climate change mitigation and adaptation. I briefly review the results of a selection of projects from the first phase of that program. Three of the key research questions posed by these projects are: Who emits the most? Who is most vulnerable to climate impacts? Does adaptation protect the most vulnerable?

\section{Who emits the most?}

There is a strong correlation between household income and household emissions. A quantitative study by Fahmy et al. (2011) explored the nature of this link by compiling a new dataset that combines information on household income, consumption of household fuels, private road travel, public transport use, and domestic and international aviation. The report provides new insights into who is responsible for emitting how much carbon dioxide and identifies the relative contributions of different aspects of consumption to household carbon emissions (Fahmy et al. 2011). The relationship between emissions and income is clear. Higher income households generally emit more; lower income groups emit the least ${ }^{[2]}$. This observation may imply a level of injustice, if it is the case that lower emitting groups are also more vulnerable to the climate impacts caused by greenhouse gas emissions. Fahmy et al. go on to use the database of household emissions to analyze the social impacts of mitigation policies, which in some cases have important negative implications for social justice (see also Speck 1999).

\section{Who is most vulnerable?}

Climate impacts will vary between climatic zones and local areas in the UK (HR Wallingford 2012). However, the harm, or opportunities, that will result from these changes in climate will also vary between social groups within and across different localities. Furthermore, different climate impacts will affect groups differently.

The current evidence base on the social distribution of climate impacts and vulnerability is generally poor. Studies have looked at the relationship between impacts such as heat and mortality (e.g., Basu and Samet 2002, Mirabelli and Richardson 2005, Hajat et al. 2007), sometimes with a social analysis of the results. Literature from the U.S., drawing on the rich tradition of environmental justice research in that country, has analyzed the impact of extreme weather such as heat waves from a social perspective, for example to analyze the distribution of harm, again, usually mortality, across different ethnic groups (e.g., Klinenburg 2002, O'Neill et al. 2005, Morello-Frosch et al. 2009), as well as other social effects associated with heat waves, including stress, social disruption, violence, and increased crime levels (Simister and Cooper 2005). Recently, similarly social-based analyses of heat have begun to emerge in the UK (e.g., Brown and Walker 2008, Wolf et al. 2010).

Following the environmental justice angle, in the UK, where flooding has been a more traditional impact, a small number of studies have looked explicitly at flood vulnerability and environmental inequalities (e.g., Tapsell et al. 2002, Fielding et al. 2005, Thrush et al. 2005, Walker et al. 2006) with a specific Environment Agency research programme focusing on the social aspects of flood management published in 2005 (EA 2005). This literature did not explicitly focus on flooding in the context of climate change or changes in future risk, however.

More specific research on the social processes that drive vulnerability is not yet widespread. A Scotland and Northern Ireland Forum for Environmental Research (SNIFFER) report in 2009 gave an overview of many of the social issues that are relevant to climate change and identified gaps in research (CAG Consultants 2009). The JRF Climate Change and Social Justice program represents the first effort since this SNIFFER report to strategically improve the evidence base and communicate issues directly to policy makers and wider stakeholders.

Below, three recent studies from the JRF program are reviewed, each looking at different but overlapping aspects of social vulnerability to climate change, namely: Zsamboky et al. (2011) on the impacts of climate change on disadvantaged coastal communities, Benzie et al. (2011) on vulnerability to heat waves and drought, and Lindley et al. (2011) on climate change, justice, and vulnerability. Table 1 provides an overview of the socially contextual factors that determine vulnerability to climate change, based on an interpretation by the author, drawing on these three projects. In it, I reinterpret the analysis in the original sources, which 
Table 1. Overview of socially contextual factors that determine vulnerability to climate change.

\begin{tabular}{|c|c|c|c|}
\hline Study & Zsamboky et al. (2011) & Benzie et al. (2011) & Lindley et al. (2011) \\
\hline $\begin{array}{l}\text { Impacts } \\
\text { considered }\end{array}$ & Coastal flooding, heatwave & Heatwave, drought & Fluvial and coastal flooding, heatwave \\
\hline Methods & $\begin{array}{l}\text { Community-level focus } \\
\text { groups, literature review }\end{array}$ & Literature review, stakeholder interviews & Extensive literature review \\
\hline $\begin{array}{l}\text { Determinants } \\
\text { of } \\
\text { vulnerability }\end{array}$ & $\begin{array}{l}\text { Age } \\
\text { Existing health conditions } \\
\text { Self-perceptions of } \\
\text { vulnerability } \\
\text { Household resources } \\
\text { (poverty) } \\
\text { Livelihoods, particularly } \\
\text { where related directly to the } \\
\text { coast } \\
\text { Reliance on coastal } \\
\text { infrastructure } \\
\text { Housing quality } \\
\text { Geographical isolation, e.g., } \\
\text { island communities } \\
\text { "Blighted" neighborhoods, } \\
\text { e.g., stigma or crash in } \\
\text { property values related to } \\
\text { perceived climate risks } \\
\text { Community deprivation, } \\
\text { including capacity of local } \\
\text { authorities } \\
\text { Access to affordable } \\
\text { insurance }\end{array}$ & $\begin{array}{l}\text { Exposure } \\
\text { Housing quality } \\
\text { Occupation } \\
\text { Physical neighborhood characteristics including } \\
\text { urban heat island, green spaces, etc. } \\
\text { Geographical location, e.g., in drought zone or } \\
\text { urban/rural } \\
\text { Sensitivity } \\
\text { Age } \\
\text { Health and disability, including mental and } \\
\text { physical health conditions } \\
\text { Lifestyle, including drug use, outdoor activities, } \\
\text { etc. } \\
\text { Adaptive Capacity } \\
\text { Education } \\
\text { Access to information and knowledge } \\
\text { Tenure } \\
\text { Transience } \\
\text { Perception } \\
\text { Household size } \\
\text { Household use of resources, e.g., water use } \\
\text { Income } \\
\text { Lifestyle flexibility, including alternative } \\
\text { employment and leisure options } \\
\text { Social capital and community cohesion } \\
\text { Access to social networks } \\
\text { Access to political power and representation } \\
\text { Institutional jurisdiction, e.g., quality of local } \\
\text { health services, local authorities, water companies, } \\
\text { etc. }\end{array}$ & $\begin{array}{l}\text { Personal factors } \\
\text { Age } \\
\text { Health } \\
\text { Education, knowledge, and awareness } \\
\text { Family size } \\
\text { Gender, ethnicity } \\
\text { Mobility } \\
\text { Housing tenure } \\
\text { Occupation } \\
\text { Transience, including tourists, travelers, homeless } \\
\text { Access to decision making } \\
\text { Income } \\
\text { Insurance } \\
\text { Environment factors } \\
\text { Physical attributes of neighborhood, including } \\
\text { green space, urban heat island, overcrowding } \\
\text { Building characteristics, including elevation and } \\
\text { access to air conditioning } \\
\text { Social factors } \\
\text { Social networks } \\
\text { Social characteristics of neighborhood, including } \\
\text { isolation, fear of crime, public cool spaces, } \\
\text { inequality, trust, unemployment, population } \\
\text { turnover } \\
\text { Institutional regimes, e.g., nursing homes, loss of } \\
\text { individual autonomy } \\
\text { Local authority resources } \\
\text { Experience of previous extreme weather event(s) } \\
\text { Access to social/ health services }\end{array}$ \\
\hline
\end{tabular}

use slightly different framings to describe socially contextual factors to the ones summarized in this table.

\section{Coastal vulnerability}

Zsamboky et al. (2011) look at the impacts of climate change on disadvantaged coastal communities. They found a strong social dimension to the exposure of people to coastal flood risk, but also a number of links between deprivation and the ability of households and communities to respond to flood events and adapt to future threats.

Coastal communities in the UK tend to be characterized by high levels of youth out-migration and a corresponding in-migration and concentration of older people, as well as transient groups, including tourists, who are identified as being most sensitive to climate impacts. Coastal communities are particularly vulnerable because of their high reliance on coastal infrastructure, ecosystems, and communications, which are especially susceptible to damage and disruption from climate impacts, namely sea-level rise, storm-related damage, coastal erosion, and flooding.
A high economic reliance on seasonal employment related to tourism also heightens the sensitivity of coastal communities to extreme weather events and possibly long-term climate change, although climate change may present opportunities for tourismrelated employment as well. Local health, social, and emergency services are also put under pressure during the tourism season, reducing the capacity of these services to support local populations in the event of extreme events such as heat waves or floods, and rendering tourists themselves at higher risk.

The physical isolation of some coastal communities, particularly those on islands and remote coastlines, adds to their vulnerability, as do the generally old and poor-quality housing stock and belowaverage income levels associated with deprived coastal communities. Zsamboky et al. (2011) highlights the risk that certain coastal towns and villages become "blighted" by the perception of high risks from coastal change and therefore suffer from falling property values, lost job opportunities, and lower investment, and possibly even less flood defence protection from central government, leading to further social deterioration and increased vulnerability. 
Vulnerability to high temperatures

Benzie et al. (2011) examine the concepts of vulnerability and resilience as they are used by the climate change community and relate these to the concept of social justice. They find that there is likely to be a strong social dimension to climate change vulnerability in the UK. The report focuses on the complexity of social vulnerability to high temperatures.

In the UK, vulnerability to high temperatures has previously been understood as a function of health and a matter for the health service (DoH 2010). Although accurate, this physiological focus on sensitivity fails to account for the social processes and social context that determine who is able to anticipate, cope with, and adapt in order to avoid harm during heat waves.

There are spatial patterns to the distribution of vulnerability to high temperatures; for example, urban residents are more exposed (Hajat et al. 2007) and within towns and cities it is often deprived areas that are most likely to be located within the center of urban heat islands (UHIs). Deprived inner-city communities are also less likely to have close access to cool spaces such as green parks, gardens, or woodlands. Social factors are also important determinants of vulnerability, although research in this area is generally lacking.

Social cohesion at the community level, including ethnic or faithbased communities that span different urban neighborhoods, can help to identify vulnerable people and offer support during heat waves; such informal networks often replace official medical or social services, particularly where population turnover is high and trust between social groups and official services is low, as in some deprived urban neighborhoods (Brent Council 2009). In this respect, the presence of strong communities and high social capital may sometimes be higher in some deprived neighborhoods than in some higher income neighborhoods, e.g., suburban commuter districts.

Some studies indicate a link between social isolation and mortality during heat waves (e.g., Klinenberg 2002), whereas others identify stronger links between mortality and residency in care homes (e.g., Brown and Walker 2008). Welfare losses from heat, as opposed to mortality, including discomfort, distress, morbidity, violence, and social unrest, have received much less attention in the literature, but may also be concentrated in deprived inner-city areas (Benzie et al. 2011). Studies have found links between ethnicity and vulnerability to heat (e.g., Basu and Samet 2002, Morello-Frosch et al. 2009), depending on nonphysiological factors such as employment (Mirabelli and Richardson 2005), education, and levels of air conditioning (O’Neill et al. 2005).

Many studies find a link between age and vulnerability to high temperatures (e.g., Fouillet et al. 2006), but it is also important to note the role of risk perception among all groups (Grothman and Patt 2005). Various studies show that people who do not perceive themselves to be at risk are less likely to take measures to prevent the effects of heat stress, even when they are in fact at high risk (Abrahamson et al. 2009, Wolf et al. 2010). One study looked at the links between employment and climate change vulnerability, uncovering an additional social layer of vulnerability whereby people's occupation exposes them to a greater level of climate risk, for example lower-paid, unskilled jobs, e.g., outdoor manual laborers, train drivers, or factory workers, are higher risk than higher paid, high-skill jobs, e.g., those in air-conditioned offices (TUC 2009). One key finding of this literature is that vulnerability to climate events is highly dependent on local context, and that a better account of individuals' and groups' adaptive capacity is needed to understand the social nature of vulnerability in each case (e.g., Brown and Walker 2008).

\section{A socio-spatial index of vulnerability}

Lindley et al. (2011) identify the determinants of vulnerability to heat waves and floods and use these to develop a spatially explicit index of vulnerability that accounts for the social nature of sensitivity, exposure, and adaptive capacity. The results constitute the first quantitative representation of the potential for future losses in well-being that take explicit account of the social nature of vulnerability. In total $8 \%$ of English neighborhoods are estimated to have extremely high flood-related social vulnerability, with a strong concentration of vulnerability in deprived urban and coastal areas (38\% of the areas are within 2 $\mathrm{km}$ of the coast). These areas are represented as having low capacities to prepare, respond, and recover from flood events, according to the index. The specific variables that influence the distribution of social flood vulnerability include: lack of gardens and green space, which help to regulate run-off flows; a proxy measure of insurance availability, based on current flood probabilities; low income; poor knowledge; and low mobility.

Lindley et al. (2011) also produced a similar index for social vulnerability to heat. A similar proportion of neighborhoods are estimated to have extremely high social vulnerability to heat as to flooding: $9 \%$ in this case. Again, there is a strong urban dimension to the results, particularly in London, which has three times the mean level of heat vulnerability compared with other regions and $40 \%$ of all of the extremely vulnerable neighborhoods in England. Interesting detail emerges in the disaggregated results, which show, for example, a low capacity to respond to high temperature events in remote rural areas that are isolated from medical services, even though exposure is not particularly high in rural areas. There is also a strong coastal component, which is influenced by the adaptive capacity indicators rather than the signal of increased exposure from higher temperatures, underlying the dominantly social nature of vulnerability to climate change.

Taken together, the two aggregate indices of social vulnerability show the significant overlap between vulnerable neighborhoods to multiple climate impacts; fully $64 \%$ of the extremely socially vulnerable neighborhoods to flooding are also classified as extremely vulnerable to heat. This has significant implications for the design of adaptation strategies: If the same social groups tend to be vulnerable to multiple climate impacts, then a key element of adaptation strategy should be to protect and build resilience among, and to consult with, these most vulnerable groups.

\section{Does adaptation protect the most vulnerable?}

Adaptation implementation is in its early phases in the UK. Despite a growing body of research and an improved level of awareness among decision makers of the need to adapt, specific adaptation actions are few and difficult to identify (ASC 2011). Nevertheless, the JRF program has undertaken some case studies to assess emerging lessons on whether adaptation offers protection to the most vulnerable. 
Planned vs. autonomous adaptation

Adaptation can either be planned, usually by a national or local government, or autonomous, i.e., undertaken by private actors in response to their own calculation of costs and benefits (Smit and Pilifosova 2001). Planned adaptation should be carefully considered; the scope for considering social justice issues should be high. Autonomous adaptation may occur within narrower contexts, and the potential for maladaptation may be higher. Maladaptation is generally understood as those actions taken ostensibly to avoid or reduce vulnerability to climate change that impact adversely on, or even increase the vulnerability of, other systems, sectors, or social groups (Barnett and O'Neill 2010).

Improving water efficiency in response to drought risk The southwest of England is projected to become much drier as a result of climate change, particularly in the summer, with the upper end of climate projections (at the $10 \%$ probability level) for summer precipitation showing reductions of up to $50-70 \%$ under a high emissions scenario (UK Climate Projections 2009). This region also happens to have the fastest-growing population in the UK (ONS 2003) with the number of households projected to increase by $36 \%$ by 2030 (DCLG 2009). The southwest is also one of the most popular tourism destinations in England, with over 21 million visits per year, a figure that is also projected to rise because of changing patterns in the tourism industry and also because of climate change impacts elsewhere in Europe (EEA 2008). Improving water efficiency is therefore a priority for South West Water, the utility company that manages and delivers water services in the region.

However, water affordability is already a serious issue in the southwest, where prices are around $40 \%$ higher than in other regions of the UK, because of a mixture of legacy, infrastructure, and tourism factors. Delivering affordable water efficiency is therefore the additional challenge.

Benzie et al. (2011) examined a pilot project by South West Water to introduce a Rising Block Tariff for water customers. In theory, this tariff structure incentivizes water efficiency while delivering affordable water to all. It offers three differently priced "blocks" of water use: Block 1: "essential use" at $73 \%$ of the standard unit price; Block 2: standard price (a buffer); Block 3: "premium use" at $181 \%$ of the standard unit price.

The theory is that users who reduce their use are rewarded with cheaper water, and those who chose to use more pay a premium for doing so. The system relies on there being a free and equal choice between households on how much water they use. However, Benzie et al. (2011) show that water use requirements differ between households; some are less able to reduce their water use, as a result of household size, certain medical requirements, or even as a result of tenure and inflexibility to fit water-saving devices or inability to purchase water-efficient technologies, e.g., new washing machines. Such households, if on low incomes, may be unfairly penalized by the introduction of a Rising Block Tariff system, raising the prospect that water efficiency schemes could push more households into a situation of "water poverty," defined as spending more than $3 \%$ of disposable income on water bills (Fitch and Price 2002).

The case study also revealed the role of support schemes that protect low-income households from water poverty where metering and new tariff structures are in place. In the southwest, the WaterSure scheme caps bills for qualifying households, i.e., those on low incomes or with defined medical requirements, and the WaterCare scheme aims to improve water efficiency and provide support to households in debt with water companies. Thus, efficiency incentive schemes, including water metering and new tariff structures, are not inherently regressive and do provide the potential to address climate risks, i.e., drought, in socially just ways, provided that they are always implemented in tandem with support schemes for vulnerable households.

Benzie et al. (2011) and the independent Walker Review of affordability and water charging (Walker 2009) identify various features of the water sector that are important for maintaining affordability and make various recommendations to ensure that water poverty is avoided as a consequence of maladaptation to climate change. In this case, autonomous adaptation, i.e., using pricing mechanisms to address resource scarcity and reduce risks, only avoids being unjust because consumer rights are well represented in the heavily regulated water sector.

\section{Future flood insurance}

Flood insurance in the UK is currently governed by an agreement between the state and the insurance sector, known, in its most recent incarnation, as the "Statement of Principles." In short, the state commits to provide flood defences and prevent development in very high-risk areas, in return for a commitment from insurers to provide insurance cover to all households and most small businesses (see Crichton 2002). This agreement is due to expire in 2013, stimulating a lively debate between insurers, the government, and various stakeholders on what should replace it. The JRF recently published a "viewpoint" report that addresses the social justice aspects of this debate (O'Neill and O'Neill 2012).

One in six homes in England is currently at risk from flooding (EA 2009), and low-income households are the likeliest to be uninsured and the least able to recover from the financial impacts of flooding (Pitt 2008). Flood risk is increasing in the UK as a result of increased development, i.e., more and higher value homes, and climate change, including changing precipitation patterns and sea level rise. Looking into the future, there is a tension between creating disincentives to live and develop in flood zones and penalizing people who already live there. If the insurance market were left to adapt autonomously by simply pricing the actual risk for each household, insurance rates would drive demand for housing in low-risk zones, and therefore raise property values, while high-risk areas would become cheap, attracting low-income households, blighted and potentially uninsured or uninsurable, creating significant inequalities and social injustice (O'Neill and O'Neill 2012).

Alternative, nonmarket, insurance models exist and are common in other European countries, where the state often plays a larger role. O'Neill and O'Neill (2012) explain how different concepts of fairness imply different insurance models and argue strongly for a more solidaristic flood insurance regime in the UK. The case of flood insurance, as an example of autonomous adaptation where risk is priced, shows the inability of some forms of adaptation to protect the most vulnerable and a much more worrying possibility that maladaptation may significantly increase the vulnerability of some groups to climate change. 


\section{The Heatwave Plan}

Temperatures in the south of England are projected to increase significantly over coming decades, with extreme heat wave events in particular likely to cause significant harm and economic damage (Stott et al. 2004, Metroeconomica 2006). Demographic trends in parts of England, particularly the southwest, are likely to increase the population's vulnerability to high temperatures, largely as a result of increases in the number of older people, the proportion of whom is projected to rise from $22.5 \%$, already above average, to $29 \%$ by 2031 , and increased numbers of tourists.

The only current strategy for explicitly managing risks relating to high temperatures in the UK is the Heatwave Plan for England and Wales, led by the Department of Health. The existence of the strategy is in part a reaction to the unforeseen impacts of the 2003 heat wave in Europe, which led to the premature deaths of around 2000 people in the UK (Metroeconomica 2006) in addition to 30,000 deaths and billions of Euros' worth of damage across mainland Europe (De Bono et al. 2004).

The Heatwave Plan relies on various tiers of governance to "cascade" down responsibilities during heat wave events. Different levels of alert are defined within the plan and are triggered once weather forecasts exceed certain thresholds (see DoH 2010, 2011 for details).

Benzie et al. (2011) interviewed various "responsible authorities" under the Heatwave Plan and other relevant stakeholders to examine their understanding of "vulnerability to high temperatures" and to see how the concept of vulnerability was operationalized in practice. Unsurprisingly, given the complexity and lack of an evidence base identifying vulnerable people, there is some confusion and an oversimplification of vulnerability in practice, which tends to revert to health-based definitions of vulnerability. This tends to ignore the social processes that determine vulnerability and therefore misses opportunities to build resilience to high temperatures, rather than merely to respond during emergency situations. In many cases it is unlikely that the most vulnerable people will receive support during heat wave events, largely because health services are not able to identify who is most vulnerable.

The case study found that resources for implementing the Heat wave Plan were severely limited, and responsibility to implement the plan fell mostly on emergency planning departments within local government and health care professionals. This precludes the potentially crucial role of local stakeholders who benefit from a more detailed understanding of vulnerability and climate change, including social services, climate change partnerships, researchers, and, in particular, community groups.

The role of stakeholders with the ability to help build resilience to high temperatures, for example spatial planners and educators, is not yet a feature of Heatwave Plan implementation, according to Benzie et al. (2011). However, a key recommendation in the report is to go beyond the Heatwave Plan, which is understandably focused mostly on health and emergency response, given its remit, and to take a much more proactive and integrated approach to build resilience to high temperatures in the UK in ways that explicitly promote social justice and equity.
Quadruple injustice

These cases highlight the social nature of vulnerability and the uneven distribution of vulnerability to climate change. They also highlight the potential for maladaptation to increase certain groups' vulnerability, especially autonomous maladaptation, and the uneven and uncertain benefits that adaptation might bring to certain social groups in the UK.

In conclusion, it is possible to identify a "quadruple injustice" to climate change within the UK. Certain disadvantaged groups, including those on low incomes, the socially marginalized, and older people: emit the least; may be negatively impacted by mitigation policies; are most vulnerable to climate impacts; and, may be negatively impacted by adaptation policies. However, these groups are diverse and there is not always a uniform correlation between social disadvantage and emissions or vulnerability. Sometimes the reverse is true and there will be various exceptions. Identifying the quadruple injustice is not intended to imply a determinist view of vulnerability to climate change. Instead it aims to highlight the social nature of climate change causes and consequences, with a view to influencing policy responses.

This presents a particular set of challenges to adaptation decision makers. First, it raises questions of procedural justice. How can the voices of the most vulnerable be heard in the design and implementation of adaptation policies? It has been shown that the implementation of the Heatwave Plan in England and Wales has so far failed to involve vulnerable groups, or organizations that represent vulnerable groups, in the process of identifying who is vulnerable or in delivering emergency response services during heat wave events. However, the involvement of the Consumer Council for Water in the Rising Block Tariff trial in the southwest of England is evidence of a more participatory decision-making process, which also happens to result in a more just outcome (Benzie et al. 2011). Given the complexities involved in adaptation policy design, including the treatment of complex and uncertain science and the normative choices relating to risks that characterize adaptation, it is both difficult and yet essential that vulnerable groups be brought into adaptation decision making.

Second, questions of substantive justice have been raised, particularly with respect to autonomous adaptation and, most of all, where unmediated market forces are employed to deliver efficient adaptation outcomes, whether these are in the pricing of risk (via free market insurance models) or via scarcity and price signals (via water metering).

Third, there is the potential for adaptation to enhance social justice, although this has not been the focus of this paper. Adaptation measures, for example the creation of sustainable urban landscapes that offer free, cool public spaces and reduce flood risks, could improve the quality of life for residents and facilitate more cohesive community living spaces.

\section{DISCUSSION}

Methods

This paper began with a brief review of methodologies used to inform adaptation decision making. This analysis has implications for the governance of adaptation. On one level, overreliance on top-down assessment techniques may tend to hide the 
social nature of vulnerability and lead to adaptation strategies that fail to protect the most vulnerable. This would be the consequence of focusing on the size of a risk, or its aggregate costs, rather than on the social nature of the risk: who will suffer harm as a result of that risk.

As has been seen from the case studies, vulnerability to multiple climate impacts tends to overlap for certain social groups, namely those with low adaptive capacity, who now tend to be marginalized and disadvantaged in society. The implications of this for adaptation governance are that more bottom-up analyses should be used to inform adaptation policy, incorporating procedural elements, such as more consultation with vulnerable groups, as well as methodological elements that base climate risk assessment more on current climate vulnerability and that focus more on identifying cross-cutting issues from different sectors.

The UK Climate Change Risk Assessment provides an interesting case. Although initially designed as an impacts-based risk assessment, the CCRA methodology was modified to better account for the social aspects of risks, perhaps partly in response to the evidence generated and put forward by the Joseph Rowntree Foundation. The CCRA methodology now includes a stage (step 5) to explicitly consider equity issues and social vulnerability. Within this stage, broad clusters of risks have been assessed using a Social Vulnerability Checklist (HR Wallingford 2010). An evidence review report on social vulnerability to climate change impacts (Collingwood Environmental Planning, unpublished manuscript) was also prepared as part of the CCRA process to inform decision makers, though this has not yet been made public. Step 7 of the CCRA methodology, which develops risk metrics for each risk, also provides the opportunity to develop social metrics that can be used to measure changes in risks relevant to social justice, e.g., changes in the number of deprived households at risk from flooding (see HR Wallingford 2010).

In these ways, the social nature of vulnerability is recognized in the CCRA, and attempts have been made to update the methodology to better account for social vulnerability. Top-down assessments can therefore be carried out in ways that do draw attention to the social nature of vulnerability and risk, although current evidence gaps make this difficult in practice.

\section{Governance}

The quadruple injustice of climate change challenges adaptation governance to become more just and to deliver more just outcomes. I introduce the concept of a new policy concept to transfer funds between high emitters and the vulnerable, based on the logic of the quadruple injustice.

Public attitudes to fairness represent a barrier but also an opportunity for designing new, socially accepted climate change policies. Another report from the JRF Climate Change and Social Justice programme (Horton and Doran 2011) used focus groups to look at people's sense of fairness in relation to behaviors and rules governing climate change. For example, they looked at collective antipathy toward "freeriding" behavior and public support for rules to prevent excessive consumption, specifically in situations of resource scarcity, such as climate change $\left.{ }^{[3]}\right)$. The report concludes that climate change regulations do not need to appeal solely to self-interest and to cost-saving opportunities, as many regulations and policy initiatives currently attempt to.
Instead, regulations may be more successful if they appeal to people's sense of fairness, based on the link between excessive consumption, i.e., emissions, and climate change (Horton and Doran 2011). Although the focus groups did not explicitly ask people about their sense of fairness in relation to adaptation, the results present an interesting question: could people's sense of fairness be harnessed to address the quadruple injustice of climate change by transferring resources from high emitters to the most vulnerable?

The logic behind this question is that a scientifically robust causal link can be established between excessive consumption, e.g., driving a high-emitting SUV or frequent flying, physical climate change, and impacts on vulnerable people, e.g., flooding a family living on low income. Although it is unlikely that an acceptable scheme could be designed for direct payments between emitters and vulnerable groups, there may be public support for policies that use revenues from taxes on high-emitting behavior to compensate or protect vulnerable groups, or preferably to invest in building resilience among vulnerable people. This, after all, is the logic applied to global negotiations on climate change, in which developed countries have agreed to provide significant financing to help the most vulnerable countries adapt, via mechanisms such as the Green Climate Fund and the Adaptation Fund, in recognition of their historical emissions and greater financial capacity ${ }^{[4]}$. Public awareness of climate change, vulnerability, and adaptation would need to improve significantly before the fairness aspects of such a policy could be widely understood and accepted, but perhaps in future, similar mechanisms could be applied within countries to fund investment in socially just adaptation.

\section{CONCLUSION}

In this paper I have reviewed the first wave of projects in the UK that address the social nature of vulnerability to climate change. At the time of their instigation, these projects were addressing relatively new territory in terms of adaptation research in European countries. The findings therefore represent a tentative and initial exploration of the nature of vulnerability. Further examination of the issues raised, including additional case studies from other countries and ex-post analyses of the impact of climate-related events on different social groups will be helpful. In particular, more insights are needed on the scope for adaptation interventions to reduce, or indeed to exacerbate and reinforce, patterns of social vulnerability.

Although equity and justice are well-established concepts in global climate change governance (Paavola and Adger 2002), they have traditionally received much less attention at the national and subnational levels (Thomas and Twyman 2005). However, the results highlighted by this paper are broadly supported by emerging examples from other places, especially in the U.S., for example, the state of California (Cooley et al. 2012), and the cities of Phoenix and Philadelphia (Uejio et al. 2011) and New York (see Bardy 2010), where the tradition of environmental justice research and activism has evolved to consider the explicit social nature of vulnerability to climate.

The existence of a strong social dynamic in climate vulnerability raises issues for the governance of adaptation. The social distribution of vulnerability should influence the way in which policy makers interpret and use climate vulnerability indicators. 
There is a significant and growing interest in such indicators as a tool to support adaptation decision making, for example by identifying hotspots of vulnerability at the local level and to inform climate risk assessment and adaptation planning (Füssel 2009, EEA 2012).

The complex nature of social vulnerability raises two issues. First, the socio-spatial detail of indicators should be improved to better reflect layers of social vulnerability. Second, top-down assessments, such as indicator based assessments, should be complemented by bottom-up assessments with input from a variety of stakeholders, including those that are well placed to identify vulnerable groups and individuals, such as community groups and social services. Responding to these issues requires improved socioeconomic data for inclusion in vulnerability indicators and an open-minded approach to adaptation governance, in terms of who is involved in defining and assessing vulnerability, climate risk, and in the design and implementation of adaptation strategies and policies.

At least in the European context, social justice has so far not been a key organizing principal or an explicit objective of national or local adaptation, despite the progress that many European countries have made in adaptation planning. Given the explicitly social nature of vulnerability to climate change, as explored above, a clearer focus on justice is warranted. Adaptation strategies should not be afraid to state their normative objectives. Achieving social justice and building the resilience of the most vulnerable individuals and groups in society should be one of the core objectives of adaptation.

${ }^{[1]}$ For example, the current coalition government in the UK chose "fairness" as one of their three core values in the coalition agreement: http://www.general-election-2010.co.uk/2010-generalelection-manifestos/election-2010-coalition-government-programme. pdf. The Scottish Government declared: "The Scottish Executive has put delivering social justice at the heart of our Programme for Government" in its report "Social Justice - A Scotland where everyone matters": http://www.scotland.gov.uk/Publications/1999/11/ SocialJustice

[2] This analysis does not include emissions related to consumption, which are likely to provide different insights, although the overall correlation between income and emissions is expected to remain.

${ }^{[3]}$ Climate change can be understood as a resource scarcity issue in terms of the atmosphere's limited capacity to absorb greenhouse gases, the report argues. Resource scarcity is a one framing of problems that is likely to elicit feelings of cooperation and unfairness in public attitudes.

[4] The historical nature of these emissions are pertinent to the global debate, but problematic when applied to transfers between emitters and the vulnerable within current generations; for example, an individual may question the credibility of claims for compensation between members of the same generation when current climate impacts are the result of emissions more than 20 or 30 years in the past). I do not set out to explore this concept in detail, though a discussion on these issues would be welcome.

Responses to this article can be read online at: http://www.ecologyandsociety.org/issues/responses. php/6252

\section{Acknowledgments:}

The author wishes to thank Sida, the Swedish International Development Cooperation Agency, for support.

\section{LITERATURE CITED}

Abrahamson, V., J. Wolf, I. Lorenzoni, B. Fenn, S. Kovats, P. Wilkinson, W. N. Adger, and R. Raine. 2009. Perceptions of heatwave risks to health: interview-based study of older people in London and Norwich, UK. Journal of Public Health 31 (1):119-126.

Ackerman, F. 2009. The Stern review vs. its critics: which side is less wrong? Stockholm Environment Institute-US Center, Tufts University, for Economics for Equity and the Environment Network, Portland, Oregon, USA.

Adaptation Sub-Committee (ASC). 2011. Adapting to climate change in the UK: measuring progress. Adaptation SubCommittee, London, UK.

Adger, W. N., N. W. Arnell and, and E. L. Tompkins. 2005. Successful adaptation to climate change across scales. Global Environmental Change 15:77-85. http://dx.doi.org/10.1016/j. gloenvcha.2004.12.005

Bardy, G. 2010. Assessing social vulnerability to floods in two coastalmegacities: New York City and Mumbai. Rapport de Stage de Recherche, Center for International Earth Science Information Network, Earth Institute, Columbia University, New York, New York, USA.

Barnett, J., and S. O’Neill. 2010. Maladaptation. Global Environmental Change 20:211-213. http://dx.doi.org/10.1016/j. gloenvcha.2009.11.004

Basu, R., and J. Samet. 2002. Relation between elevated ambient temperature and mortality: a review of the epidemiologic evidence. Epidemiologic Reviews 24(2):190-202. http://dx.doi. org/10.1093/epirev/mxf007

Benzie, M., A. Harvey, K. Burningham, N. Hodgson, and A. Siddiqi. 2011. Vulnerability to heatwaves and drought: case studies of adaptation to climate change in south-west England. Joseph Rowntree Foundation, York, UK.

Blaikie, P., T. Cannon, I. Davis, and B. Wisner. 1994. At risk: natural hazards, people's vulnerability and disasters. Routledge, London, UK.

Bradbury, J. 1989. The policy implications of differing concepts of risk. Science, Technology and Human Values 14(4):380-399. http://dx.doi.org/10.1177/016224398901400404

Brent Council. 2009. Brent climate change: supporting evidence consultation document. Brent, UK. [online] URL: http://www. brent.gov.uk/media/2002274/CCsupportingevidenceconsultation. pdf

Brown, A., M. Gawith, K. Lonsdale, and P. Pringle. 2011. Managing adaptation: linking theory and practice. UK Climate Impacts Programme, Oxford, UK. 
Brown, S., and G. Walker. 2008. Understanding heatwave vulnerability in nursing and residential homes. Building Research \& Information 36(4):363-372. http://dx.doi.org/10.1080/09613210802076427

CAG Consultants. 2009. Differential social impacts of climate change in the UK. SNIFFER report UKCC22. CAG Consultants, London, UK.

Cooley, H., E. Moore, M. Herberger, and L. Allen. 2012. Social vulnerability to climate change in California. Report by the Pacific Institute for the California Energy Agency, Oakland, California, USA. [online] URL: http://www.pacinst.org/wp-content/uploads/2013/02/ full report31.pdf

De Bono, A., P. Peduzzi, S. Kluser, and G. Giuliani. 2004. Impacts of summer 2003 heatwave in Europe. Environment Alert Bulletin, UNEP/GRID-Europe. [online] URL: http://www.grid.unep.ch/ products/3 Reports/ew heat wave.en.pdf

Crichton, D. 2002. UK and global insurance responses to flood hazard. Water International 27:119-131. http://dx.doi. org/10.1080/02508060208686984

Department for Communities and Local Government (DCLG). 2009. Household projections to 2031, England. DCLG, London, UK. [online] URL: http://webarchive.nationalarchives.gov. uk/20120919132719/http://www.communities.gov.uk/documents/ statistics/pdf/1172133.pdf

Department of Health (DoH). 2010. Heatwave plan for England: protecting health and reducing harm from extreme heat and heatwaves. Department of Health, London, UK. [online] URL: http://webarchive.nationalarchives.gov.uk/20130107105354/http:// www.dh.gov.uk/prod_consum_dh/groups/dh_digitalassets/@,dh/@en/ documents/digitalasset/dh 116029.pdf

Department of Health (DoH). 2011. Heatwave plan for England: protecting health and reducing harm from extreme heat and heatwaves. Department of Health, London, UK. [online] URL: http://www.dh.gov.uk/prod_consum_dh/groups/dh_digitalassets/ documents/digitalasset/dh 127235.pdf

Dessai, S., and M. Hulme. 2004. Does climate adaptation policy need probabilities? Climate Policy 4(2):107-128. http://dx.doi. org/10.3763/cpol.2004.0411

Environment Agency (EA). 2005. Managing the social aspects of flooding: synthesis report. Joint Defra / Environment Agency Flood and Coastal Erosion Risk Management R\&D Programme, R\&D Technical Report SC040033/SR6. Environment Agency, Bristol, UK.

Environment Agency (EA). 2009. Flooding in England: a national assessment of flood risk. Environment Agency, Bristol, UK.

European Environment Agency (EEA). 2008. Impacts of Europe's changing climate: 2008 indicator-based assessment. EEA Report No. 4/2008. European Environment Agency, Copenhagen, Denmark. [online] URL: http://www.eea.europa.eu/publications/ eea report 2008 4/

European Environment Agency (EEA). 2012. Climate change, impacts and vulnerability in Europe 2012: an indicator-based report.

EEA Report No. 12/2012. European Environment Agency, Copenhagen, Denmark. [online] URL: http://www.eea.europa. eu/publications/climate-impacts-and-vulnerability-2012
Fahmy, E., J. Thumim, and V. White. 2011. The distribution of UK household CO2 emissions: interim report. Joseph Rowntree Foundation, York, UK.

Fielding, J., K. Gray, K. Burningham, and D. Thrush. 2005. Flood warning for vulnerable groups: secondary analysis of flood data. Environment Agency R\&D Report W5C-018/2. Environment Agency, Bristol, UK.

Fitch, M., and H. Price. 2002. Water poverty in the UK. University of Keele with the Centre for Utility Consumer Law, Keele, UK. [online] URL: http://www.cieh.org/library/Knowledge/ Environmental_protection/waterpoverty.pdf

Foresight. 2011. Foresight international dimensions of climate change. Final Project Report, The Government Office for Science, London, UK.

Fouillet, A., G. Rey, F. Laurent, G. Pavillon, S. Bellec, C. Guihenneuc-Jouyaux, J. Clavel, E. Jougla, and D. Hémon. 2006. Excess mortality related to the August 2003 heatwave in France. International Archives of Occupational and Environmental Health 80:16-24. http://dx.doi.org/10.1007/s00420-006-0089-4

Füssel, H-M. 2009. Review and quantitative analysis of indices of climate change exposure, adaptive capacity, sensitivity and impacts. Background note to the World Development Report 2010. World Bank, Washington, D.C., USA. [online] URL: http:// siteresources.worldbank.org/INTWDR2010/Resources/5287678-1255547194560/WDR2010 BG Note Fussel.pdf

Goldspink, C. 2000. Modelling social systems as complex: towards a social simulation meta-model. Journal of Artificial Societies and Social Simulation 3(2).

Grothmann, T., and A. Patt. 2005. Adaptive capacity and human cognition: the process of individual adaptation to climate change. Global Environmental Change 15:199-213. http://dx.doi. org/10.1016/j.gloenvcha.2005.01.002

Hajat, S., R. S. Kovats, and K. Lachowycz. 2007. Heat-related and cold-related deaths in England and Wales: who is at risk? Occupational and Environmental Medicine 64:93-100. http://dx. doi.org/10.1136/oem.2006.029017

Hoffmann, P., O. Krueger, and K. H. Schlünzen. 2012. A statistical model for the urban heat island and its application to a climate change scenario. International Journal of Climatology 32(8):1238-1248. http://dx.doi.org/10.1002/joc. 2348

Horton, T., and N. Doran. 2011. Climate change and sustainable consumption: what do the public think is fair? Joseph Rowntree Foundation, York, UK.

HR Wallingford. 2010. Method for undertaking the CCRA Part II - detailed method for stage 3: assess risk Project deliverable number D.2.1.1. HR Wallingford, Wallingford, UK.

HR Wallingford. 2012. The UK climate change risk assessment 2012 evidence report. Project deliverable number D.4.2.1. HR Wallingford, Wallingford, UK.

Institute of Risk Management. 2002. A risk management standard. Institute of Risk Management, London, UK. [online] URL: http://www.theirm.org/publications/documents/ARMS 2002 IRM. pdf 